ISSN: 2576-2141

\title{
Pandemonium Versus Paralysis: The Internal Experience of Adolescent Girls with Headaches
}

\author{
Elin A. Björling \\ University of Washington \\ Narayan Singh ${ }^{1}$ \\ Seattle Pacific University
}

\begin{abstract}
Mindfulness-Based Interventions (MBIs) have been shown to be successful in treating mood disorders in adolescents. However, the application of MBI treatments for non-clinical populations may be a missed opportunity. Globally, headache affects 54 percent of school-age girls, and headaches are often correlated with poor mental health. In order to better understand the internal experience of teen girls with headaches, we conducted a modified grounded theory exploring two adolescent samples totaling 39 girls (ages 13-18). This study led to a theory of Pandemonium versus Paralysis - a cycling between feeling "cluttered," or "unable to think" and feeling "dead" or "incapable of functioning." This theory illustrated the teens' internal experience of managing their stress and headaches. We then confirmed our theory within existing literature, current media, and anecdotal experience. We propose that teens oscillating between the polarities of pandemonium versus paralysis would greatly benefit from building their awareness through evidence-based therapies such as mindfulness-based stress reduction which may in turn reduce their headaches.
\end{abstract}

KEYWORDS: Adolescence, Grounded Theory, Headache, Perceived Stress.

\section{Introduction and Background}

\section{Prevalence}

Headache affects over half of adults (World Health Organization, 2016) and approximately 54\% of adolescents and children (Wöber-Bingöl, 2013). In a headache prevalence study, a school-based sample of adolescents who identified as having headaches reported an average of 12 headaches per month in a daily diary instrument (Larsson \& Fichtel, 2014). Compared to boys, girls are far more susceptible to headache, especially migraine (Wöber-Bingöl, 2013). Surprisingly, although headache is the most common pain complaint among girls ages 15-16 (Genizi, Srugo, \& Kerem, 2013), most head pain often goes untreated (Albers et al., 2015) despite the significant reported disability (Kernick \& Campbell, 2009; Lima et al., 2014; Wöber-Bingöl et al., 2014).

\footnotetext{
${ }^{1}$ Corresponding author; School of Psychology, Family, and Community. E-mail: singhn1@ spu.edu
} 


\section{Disability}

Headaches can cause extreme disability (Albers et al., 2015). For instance, a schoolbased study of 12 to 15-year-olds found that $17 \%$ of adolescents with 2-3 headaches per week directly impacted their school work or home life an average of 17 times over a 3-month period (Kernick, Reinhold, \& Campbell, 2009). In fact, Kernick and Campbell (2009) suggested that not only is the impact of headache in adolescents significant, but that the impact remains unrecognized and often goes unaddressed. Fuh and colleagues (2010), Carothers and Parfitt (2017) found that adolescents aged 13-15 with migraine reported significantly higher levels of disability than their peers with tension-type headache.

\section{Headaches, Stress and Mental health}

Compared to adolescent boys, adolescent girls are far more likely to report stress-related symptoms such as stomach aches and headaches and report more academic stress (Schraml, Perski, Grossi, \& Simonsson-Sarnecki, 2011). Girls tend to report greater levels of stress (Kudielka \& Kirschbaum, 2005), more stressful life events (Kendler, Thornton, \& Prescott, 2001), academic burnout (Salmela-Aro \& Tynkknen, 2012), and more stress-related symptoms (Wiklund, Malmgren-Olsson, Ohman, Bergström, \& Fjellman-Wiklund, 2012). Depression is also increased in adolescent girls compared to boys (Hamilton, Strange, Abramson, \& Alloy, 2015), and may be related to stressful life events (Mazurka, Wynne-Edwards, \& Harkness, 2015) or exposure to stress over time (Hankin, Mermelstein, \& Roesch, 2007; Kratt, 2018). In a study of stressful life events and substance use in adolescence, girls reported more stress from schoolwork and were more likely to report substance use than boys (Low et al., 2012). In a longitudinal study of stress in adolescents comparing grade six and grade nine Giota \& Gustaffson (2016) found that in grade six, girls and boys self-reported similar levels of academic demand, however, adolescent girls reported increased levels of stress. By grade nine, girls reported significantly greater academic demand and academic stress and reported far more mental health problems such as anxiety and depression.

In a longitudinal study of adolescents, increased anxiety and depression were positively correlated with recurrent headache four years later (Blaauw et al., 2015). Headache symptoms have also been strongly correlated with major depressive disorder in adolescents (Nardi, Francesconi, Catena-Dell-Osso, \& Bellantuono, 2013). Wang, Fuh, Juang, \& Lu, 2009) found that adolescents with migraine were more likely to report suicidal ideation as compared to adolescents without migraine. Østerås, Sigmundsson, \& Haga, 2016) found that stress and pain are positively correlated in all adolescents. Perceived stress and stressful life events are strongly correlated with headaches in adolescents (Björling \& Singh, 2016; Björling, 2009; Milde-Busch et al., 2011).

\section{Qualitative Studies of Stress and Headaches in Adolescents}

Although both headaches and stress are common in adolescents, only three studies (outside of our own) were found that explored the adolescent experience of stress qualitatively. Two of these studies explored the triggers or stressors experienced by adolescents. Florêncio, Ramos, and Silva (2017) conducted focus groups with 17 adolescents. Interestingly, adolescents with high stress indicated that family, and relationships were primary contributors to their stress, whereas adolescents with low stress reported that family and relationships were sources of positivity and calm. Spencer and colleagues (2016) explored psychosocial stress among affluent adolescent girls. Sources of stress included pressure to perform, narrow constructions of success, peer competition, and misalignments in expectations. Stress was also found to increase with age. In a study of the experience of stress in adolescent girls with 
headache (Björling \& Singh, 2017), strong themes of helplessness and lack of agency were described. Adolescent girls with headaches tended to accept their conditions and were not active agents in seeking change regarding their stress or headaches.

Although a few studies have qualitatively explored the experiences of adult headache sufferers (e.g. Peters, Huijer Abu-Saad, Vydelingum, Dowson, \& Murphy, 2005; Ruiz de Velasco, Gonzalez, Etxeberria, \& Garcia-Monco, 2003; Wilder et al.,, 2017), only one study was found to explore the experience of headache, namely migraine, for adolescents. In a qualitative exploration of the lived experience of six adolescents suffering from migraine, Helvig and Minick (2013) found three main themes: 1) maintaining control, 2) mind overload, and 3) unsettling manifestations. Maintaining control included two sub-themes: Self-Isolate, and Press on and Endure. The adolescents described unsettling manifestations of migraine in both physical (e.g. tunnel vision and nausea) and psychological (e.g. feelings of helplessness) domains.

It is not surprising that adolescents who suffer from headaches and stress are a vulnerable population. Stress and headache have been shown to be positively correlated in adolescents (Østeras, 2016) perhaps even causing a stress-headache, reinforcing cycle (Björling $\&$ Singh, 2016). And although the lived experience of stress (Florencio, 2017; Björling \& Singh, 2017; Haraldsson, 2010) and headache (Peters, 2005; Helvig, 2013) have separately been explored in adolescent girls, no theory exists to articulate the individual relationship between stress and headaches.

Therefore, in our study, we utilized a grounded theorizing approach to explore the experiences of adolescent girls suffering from stress and headache in order to develop a salient theory that fully illustrates their experience.

\section{Methods}

\section{A Grounded Theorizing Approach}

Whereas phenomenology is focused on the lived experience of the individuals being studied, grounded theory attempts to explore this lived experience to articulate a theory that helps to make sense of such an experience (Strauss and Corbin, 1994). A grounded theorizing approach allows for a range of strategies in the procedure for developing a grounded theory (Holton, 2018). Holton (2018) describes grounded theorizing as "encompassing range of empirically grounded, inductive qualitative approaches" (p. 241). In our grounded theorizing approach, we utilized constant comparison and theoretical sampling by pulling data from an existing dataset. Through this process, a defining theory emerged. We felt that given the minimal exploration of the internal experience in adolescent girls with headaches, a grounded theory exploration would be a valuable contribution.

\section{Theoretical Sampling}

An important component of grounded theory is theoretical sampling: the process of data collection for generating theory while collecting, coding and analyzing existing data. Typically, the researcher decides what data to collect next and where to find them, in order to develop a theory as it emerges (Glaser and Strauss 1967 p. 45). In our case, we utilized two samples described in detail in Table 1. Our current sample $(n=8)$, was collected in 2014 as a part of a study on mindfulness, stress, and headache (Björling, Stevens, \& Singh, 2019). For this analysis we explored group interviews related to the teens' descriptions of experiencing stress and headaches.

The second dataset was archival $(n=31)$, collected in 2008 as a part of a study on stress and headache in adolescent girls (Björling, 2009). We began by exploring the first dataset using 
open-coding. After open-coding was complete for our existing dataset, we used theoretical sampling to explore the archival dataset in order to fully form our theory. The use of an archival dataset as part of theoretical sampling in grounded theory has been recommended previously by Drauker et al. (2007).

Table 1

Characteristics of both samples

\begin{tabular}{lllllllll}
\hline Sample & Type & $\begin{array}{l}\text { Year } \\
\text { Collected }\end{array}$ & $\boldsymbol{N}$ & $\begin{array}{l}\text { Interview } \\
\text { Type }\end{array}$ & $\begin{array}{l}\text { Interview } \\
\text { Site }\end{array}$ & $\begin{array}{l}\text { Age Range } \\
\text { (Mean) in } \\
\text { Years }\end{array}$ & $\begin{array}{l}\text { Grade } \\
\text { Range } \\
\text { (Mean) }\end{array}$ & $\begin{array}{l}\text { PSS Score } \\
\text { Mean (SD) }\end{array}$ \\
\hline 1 & Current & 2014 & 8 & Group & School & $14-17(15.88)$ & $9-12(10.75)$ & $19.8(5.3)$ \\
2 & Archival & 2008 & 31 & Individual & Home & $13-18(16)$ & $9-12(10.7)$ & $19.9(6.7)$ \\
\hline
\end{tabular}

\section{Current Sample}

Recruitment. Both studies were approved by the University's Institutional Review Board prior to approaching any study participants. Participants were recruited from a high school located in an urban community (Undisclosed) in the Pacific Northwest. In both studies, the high school and associated teen health center authorized the study recruitment and procedures. Adolescent girls with headache were recruited for both studies. Teens were invited via public flyers placed in the school's teen health center. Interested participants contacted the study research assistant by phone to be screened for eligibility.

Setting. The study took place in a teen health center in an urban, public high school. School-based health centers are on-site medical and mental health facilities operated by community health agencies. They are typically staffed with coordinators, nurse practitioners, and mental health counselors. Teen health centers are available to all students and can be accessed during school hours without parental or school staff permission.

Screening. Eleven self-selected participants were screened by study staff (by phone or in person) at the teen health center for recent headache activity and one was determined ineligible due to head injury.

\section{Eligibility Criteria:}

1. A self-report of at least 3 headaches in the past two weeks.

2. Headaches are not the obvious result of a head-related disease or injury.

3. No current preventive treatment or medication for headache.

4. Not actively working on mindfulness or relaxation training.

Of the 10 eligible participants, one never responded to follow-up contact. Nine enrolled participants and their respective parents gave their consent to participate in the study. One participant dropped out of the study before it began due to academic burden. Eight participants continued and completed the full study. Study participants were compensated $\$ 75$ in retail store gift cards for their participation.

\section{Measures}

Both questionnaire and interview data were necessary to capture the full experience of participants' stress and headaches. Survey data were captured to fully articulate the frequency, incidence, disability, and symptoms of headache. Interview data were used to better understand the teens' personal experience and context of the experiences of the teen girls. 
Demographic intake. A customized demographic survey was created to capture participants' age, grade, and self-reported gender and ethnicity.

Perceived stress scale. In order to understand the stress levels of our sample, we captured self-reported stress using the Perceived Stress Scale (PSS; Cohen, 1994, 1988), a 10item questionnaire that measures the degree to which situations in one's life are appraised as stressful. The PSS is a retrospective measure of perceived stress in the past two weeks. High PSS scores have been positively correlated with increased common illnesses, and increased stressful life events. In addition, PSS scores are highly correlated with scores on other measures of stress and health behaviors. Coefficient alpha reliability for the PSS is .85.

Headache questionnaire. Headache characteristics and activity were gathered using the Diamond Headache Questionnaire (DHQ; Diamond et al., 2006). The DHQ is a 13-item, paper questionnaire that was used to capture each participant's headache characteristics, frequency, and physical symptoms that accompany their typical headache. Questions range from, "How many headaches have you had in the past two weeks?" to "Is the pain greater on one side of the head" with response options such as "always," "very often," "uncertain," "seldom," and "never." This questionnaire was modified to include demographic questions (e.g. age, grade, ethnicity).

Group interviews. Two group interviews were conducted to capture the girls' experiences of stress and headaches. These interviews were conducted at the high school, in a small conference room in the teen health center, during an elective period. Students were excused from their elective class in order to participate in this study. Each open-ended, group interview lasted about 45 minutes and focused on the teens' experiences of stress and headaches. All study participants attended and actively participated in both interviews which led to a large amount of rich qualitative data.

The first semi-structured interview focused on questions related to the teens' overall experience of stress and headaches, "What does stress feel like?" "What is stressful for you?" "How do you know when you are stressed?" The second semi-structured interview focused on headaches and included questions such as "What does a headache feel like?" "What have you noticed about your headaches over time?" and "How do headaches impact your daily life?"

\section{Analyses}

Glaserian Grounded Theory (GGT) data analysis is an iterative process using constant comparison of the data from all sources (Artinia, Giske, \& Cone, 2009). GGT begins with open coding, which is a natural form of reviewing the data and coding as much of the data as possible without regard to relevance (Glaser, 1978). Open coding leads to the emergence of a core variable. A core variable is one that appears to relate to much of the data (Glaser, 2004). Then selective coding is used to relate new codes back to this core variable, until eventually final concepts help to form the theory that feels like the best fit for each of the participants' experiences and the data that was gathered (Glaser, 2007).

Headache characteristic questionnaires were analyzed descriptively, specifically exploring frequencies and paying particular attention to the teens' descriptors. Group interviews were audio recorded and transcribed. Open-coding was done using Dedoose, version 7.0 (2016) allowing for a truly collaborative process. For an illustration of our process, see Figure 1, below. 


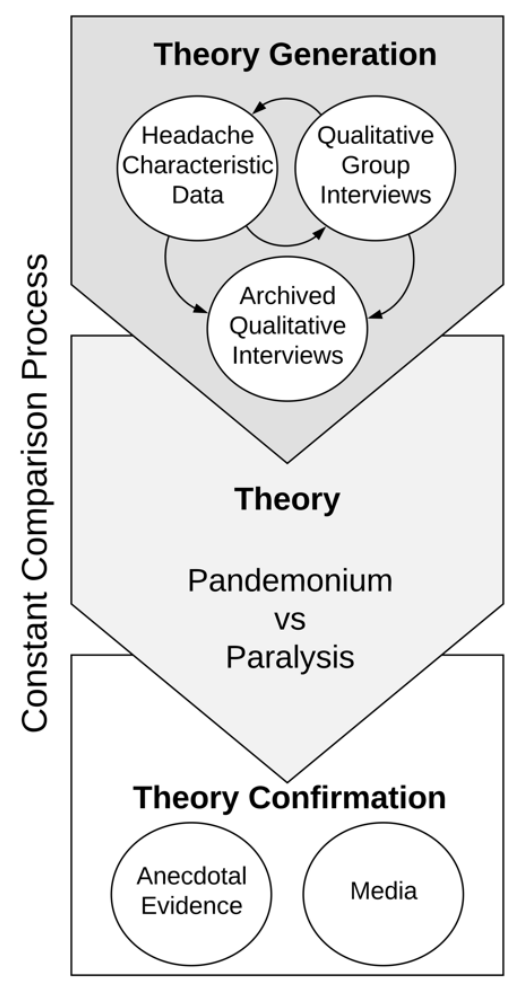

Figure 1. Flow chart of constant comparison process.

\section{Constant Comparison and Theoretical Sampling}

Open coding - Sample 1. Analysis began by open-coding the qualitative, group interview data. Transcripts, digital audio files, field notes and memos were reviewed multiple times by the first author during open-coding. During open-coding our team used in-vivo codes (King, 2008) to try to stay true to the participants' own words in articulating their experience. Initial codes included terms such as crazy, suffocating, and totally out of it. Then open-coding was conducted on the data from the headache and perceived-stress questionnaires. This data included quantitative descriptive statistics, total scores, items checked, as well as write-in responses. Subsequent codes emerged such as, out of control, lying down, and happens all the time.

Eventually, open-codes from all sources of data were reviewed by two members of the research team. From all open-codes, two core variables emerged: chaos and overwhelm. The core variables (along with associated codes) were shared with the research team and discussed as the plausible beginning of a salient theme.

Selective coding - Sample 2. In line with our grounded theorizing approach, we utilized theoretical sampling procedures to evaluate a second dataset of adolescent girls with headache. Using selective coding, we explored the data for the codes of pandemonium and paralysis. For the present study, both authors reviewed the original interview transcripts and extracted verbatim quotes if they clearly illustrated one of three categories of Pandemonium versus Paralysis: 1) pandemonium, 2) paralysis, or 3) cycling between pandemonium and paralysis. Both authors then reviewed the verbatim quotes and discussed the suitability of each quote for its assigned category. Only quotes which both authors agreed fit the assigned category were used in the final analysis.

Theory development. The first and second authors returned to the data to find relationships to the core variables. Eventually a theme emerged about the teens' struggle with maintaining a very hectic academic life and struggling with the disability associated with 
headaches and overwhelm from stress. After much discussion the authors felt clear that both stress and headache had a similar pattern among the girls as each phenomenon led to either one of two conditions: chaos, or overwhelm to which common responses were shutting down, falling apart, or numbness. These experiences, both internal and external had such enormous range, that the encompassing theory needed to include this diverse range of experiences. Initially, we played with theory titles such as "deadline versus flat line," but soon the title of "pandemonium vs paralysis" was suggested and seemed appropriately fitting for our core variables and our raw data. Once a theory was formed, raw data were reviewed several more times to ensure that almost all the data fit well within this theory.

\section{Results}

\section{Sample}

The first sample consisted of eight participants. Sample characteristics are reported in Table 1. The teens were asked to self-identify their ethnicity in an open-form question. Six participants identified themselves as "White" or "Caucasian," one identified herself as "Happa," and one identified as "European." The teens' PSS stress level scores ranged from 14 to $30(M=19.75 ; \mathrm{SD}=5.34)$, much higher than the published norms for their age range.

\section{Grounded Theory: Pandemonium Versus Paralysis}

The grounded theory of pandemonium versus paralysis seemed to be a good fit for most of the teens' data as it articulated both their experiences of stress and headaches in the interview data and the concomitant outcomes in the questionnaire data. In this theory, stress and headaches seem to be key components, lodged within this larger, revolving system of back and forth between pandemonium and paralysis. Almost like cogs in a large machine, stress and headache support the continued churning between these two polarities. See Figure 2 for an illustration of this theory.

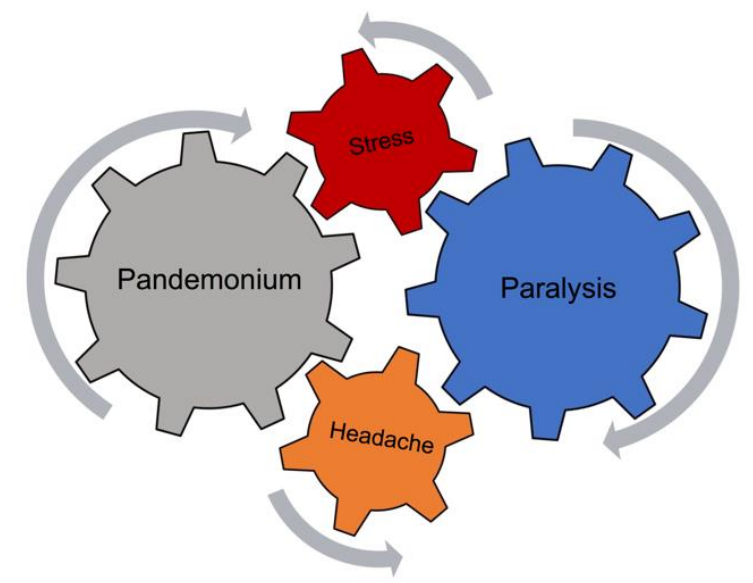

Figure 2. Theoretical illustration of pandemonium vs. paralysis with stress and headache.

Both the stress and the headaches were described as "feeding the cycle" and causing the continuation of this unavoidable fluctuation between pandemonium and paralysis. For these teens, stress and headache had a similar pattern among the girls as each phenomenon led to either one of two conditions: chaos or overwhelm. Both of these conditions were extreme. Headache chaos was described with extreme pain and inability to concentrate, whereas stress chaos was described as feeling scattered and unable to focus. Overwhelming headaches would stop you in your tracks and cause great disability, reducing activity. Overwhelming stress 
would also reduce activity and productivity by causing a sense of feeling scattered or inability to focus.

\section{The Experience of Headache: Pandemonium vs. Paralysis}

In the current sample, the teens' articulations of their headache experiences easily fit into the pandemonium versus paralysis theory. In fact, pandemonium and paralysis were almost inseparable in much of the headache data. Most participants described headache symptoms commonly associated with tension-type headache, "pain is on both sides and feels like a "tight band" [paralysis]. Some participants reported headaches with throbbing and greater pain on one side, typical of a migraine (Mayo Clinic, 2017). More than half of the participants reported headaches which began in the morning and worsened in the evening. Head movement increased head pain [pandemonium] in most of the participants and half of the girls mentioned some headache relief from lying down [paralysis]. An overview of the teens' headache characteristics is illustrated in Figure 3.

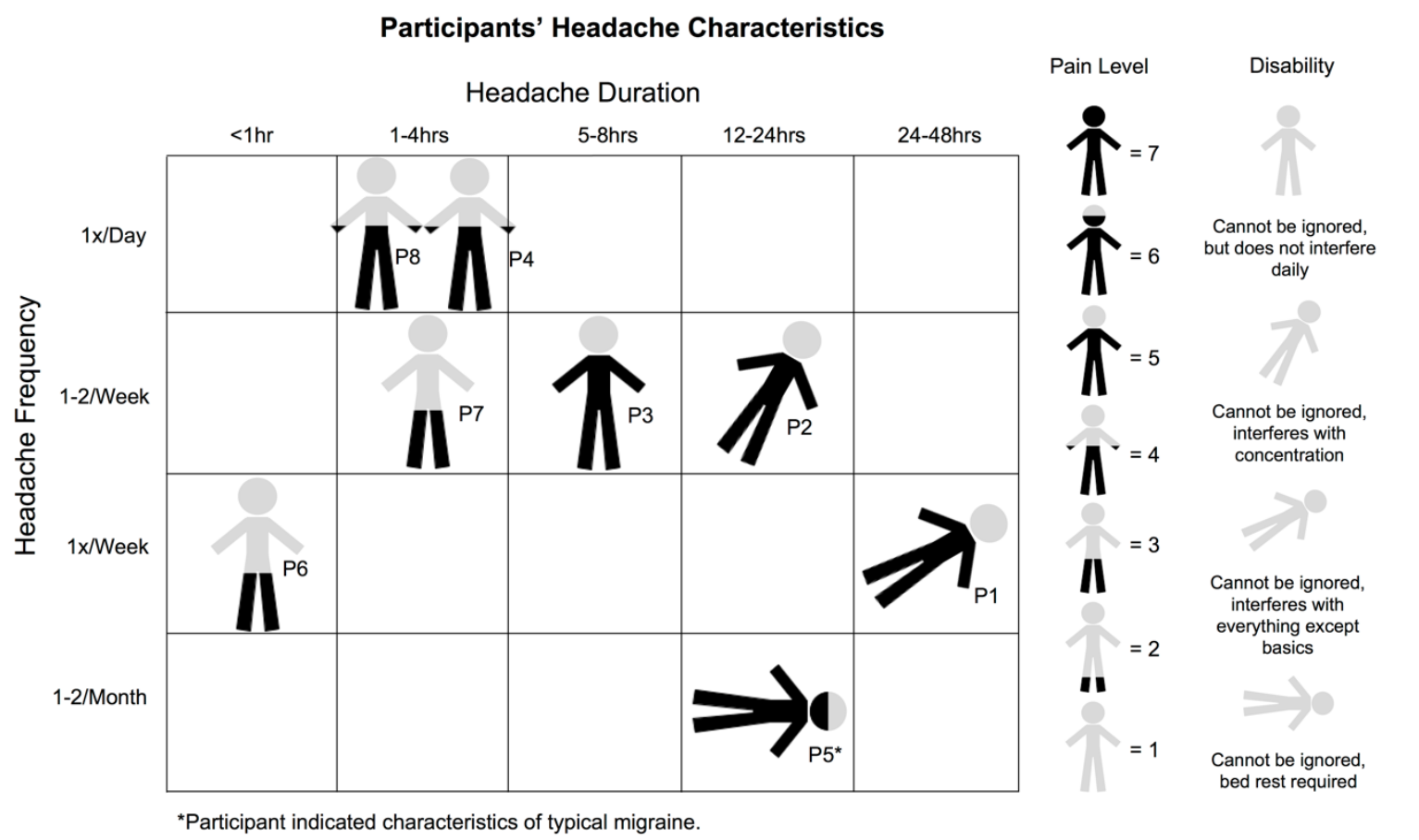

Figure 3. Characteristics of each participant's typical headache in the current sample. Frequency, duration, pain level, and disability, were measured from the Diamond Headache Questionnaire (DHQ).

Pandemonium. The frequency and symptoms of headaches fit well within the concept of pandemonium as these headaches were experienced often and added to what the teens had to deal with on a regular basis. However, many of the girls seemed resigned to the fact that headaches were out of their control and there was little they could do to change that, which seemed fitting with the paralysis component of the theory.

All eight of the girls reported one or more headaches per week. Headaches in the past two weeks ranged from 1 to 14 headaches, with an average of 4 per week. Dizziness $(n=3)$, vision problems $(n=2)$, and dual-sided head pain $(n=4)$ were also reported. Mood changes were common $(\mathrm{n}=4)$ but nausea $(\mathrm{n}=1)$ was not. Not surprisingly, "tension / stress" was the most frequently selected cause of headache $(n=5)$. One teen reported that "weather change" was "always" the cause of her headaches.

Headaches required attention from many of the teens. In the group interviews, the teens were very clear that their headaches resulted in significant disability, and disrupted school, 
outside activities, and even sleep. For example, a teen stated, "When I have headaches, I normally cannot sleep because then my head is throbbing and my head hurts. I cannot fall asleep (P6, S1)" [pandemonium]. For another teen, her headaches stopped her immediately in the middle of her day, causing her to need to stop what she was doing or head home and lie down [paralysis]. A teen with migraine headaches reported frequently experiencing the headache upon waking with a typical migraine pain level is severe (i.e. six out of seven) and significant impairment. During a migraine, she always experiences head throbbing, cold limbs, stomach pains, and loss of appetite. She reported that the pain frequently begins on the side of her head, and that she often experiences depression and pain on both sides of her head during migraines. Noise, lights, and head movement exacerbate her migraine [pandemonium]. When her migraine occurs, it interferes with her regular activities and cannot be ignored, requiring bed rest [paralysis], which she reported always relieves the pain.

Paralysis. There was a consistent theme of internal paralysis or passivity when the teens described a lack of control over both their stress and their headaches. The teens described their headaches as being out of their control, and as happening to them. Most of the girls articulated their headaches as just something to live with. "I get headaches once a day it comes and goes kind of" (P2, S1). "I get them, maybe, like once a week. They last like 20 minutes, then it kind of goes away" (P8, S1). Even when trying to manage their headaches, some girls described taking medicine, but that it had little effect. One articulation of paralysis was the description of a headache that caused the teen to stop functioning and forced her to do nothing. "Yeah, I couldn't even function. I just had to sit there and rub my temple, which didn't help much. Like nothing helped it much" (P8, S1).

Teens described environmental triggers of their headaches, all of which were out of their control, such as stress, poor sleep, or even sunlight. For instance, a teen stated, "Like going from a dark room or say a semi-dark room to really bright lights or just going outside. It's like that [snaps] and I have a headache." (P6, S1) The prominent theory of pandemonium versus paralysis was also evident in the teens' data related to their stress.

\section{The Experience of Stress: Pandemonium vs. Paralysis}

Pandemonium. The teens described their daily world as a fast-paced and non-stop. They described the difficulty of trying to get everything done. Their expectations of themselves (and their parents and teachers) were demanding. Their world was articulated as being out of their control and requiring more from them than they had to offer. These descriptions of chaos led to the emergence of the theme of pandemonium, as the girls experienced a combination of disarray, confusion, and unmanageable expectations. For instance, one teen described her experience of having too much to do: "You are very like scattered brain. And it's like, oh my gosh. You cannot concentrate on any one thing because you have to do all these things at the same time" (P2, S1). Another teen articulated her internal experience of pandemonium.

\section{I get really fidgety and really easily distracted when I know that I should be focusing on the things that are making me stressed, but I just can't. Once I realize that I am stressed, then I just get very distracted and fidgety and can't really focus on one thing. (P2, S1)}

Pandemonium was not just isolated to mental struggles, but also was illustrated in terms of physical symptoms. As one teen described, "I feel like I want to throw up all the time...when I am stressed out" (P3, S1). In contrast to pandemonium, the girls reported experiencing a polar opposite state, as a result of stress which was encapsulated by the theme paralysis.

Paralysis. The teens described that following pandemonium, they would experience shutting down, feeling debilitated, or being unable to move. Therefore, we interpreted this 
experience as being a state of psychological paralysis. Included within this theme was also the girls' passivity toward their stressors and symptoms. Many of the teens articulated the feeling of paralysis in several ways. "Like the other night, it was really bad. I sat in bed for two hours and I did not realize it. My brain kind of shut down...I thought it was just like five minutes, but it was two hours!" (P4, S1). At the same time that the experience of pandemonium and paralysis felt extreme, the teens also described this world of theirs with a certain amount of acceptance as normal and unavoidable.

Cycling between pandemonium and paralysis. This relationship between pandemonium and paralysis was also supported by the teens' descriptions of one leading to the other. One teen articulated the whole cycle of pandemonium to paralysis resulting from stress, "I think it feels like the more you get stressed (pandemonium), the more you just want to give up (paralysis), but then if you give up you will get obviously more stress (pandemonium), so it is like a recurring cycle" $(\mathrm{P} 1, \mathrm{~S} 1)$. Another teen shared that she often experienced unplanned sleep (paralysis) in response to having too much to do (pandemonium). She described her body as just shutting down unintentionally and when she awoke, she fell right back into pandemonium: "While doing homework, I will fall asleep like for 3 hours, then wake up and freak out...and it is like 9pm!" (P3, S1)

The most profound statements we heard that fit into this cycle of pandemonium versus paralysis were two teens' descriptions about how it felt knowing they have so much to do. They reported feeling paralyzed when they realized just how much they needed to get done.

P4 (S1): It's like we have to deal with so much. That's what I think of whenever I say I am stressed it's just like I know I have to do so much stuff. And you just think about all the stuff you have to do. You are like oh my gosh I have to do all this. [pandemonium]

Interviewer 1 (S1): So dealing with a lot of stuff.

P5: Yeah, I think that's more my stress thing, it's having to deal with a ton of stuff, and not being able to take a break, and just like take a moment to relax [pandemonium].

Interviewer 1 (S1): So what does that feel like? If you like put your mind into that place, that moment when you have so much to do?

P5 (S1): Suffocating, almost. Like I can't even move... [paralysis]

P6 (S1): Yeah, you can't even breathe. [paralysis]

The teens' full range of stress and headache experiences, and the cycling between the two clearly fit both the pandemonium versus paralysis theory. Teens also showed some awareness of the relationship between their stress and headaches, as described below.

The relationship between stress and headaches. Although the teens did not describe any solutions to having too much to do (pandemonium), or their resulting moments of "freak out" or "breakdown" (paralysis), they did articulate how stress and headaches are agents in this larger process. See Figure 2 for illustration.

The teens recognized the relationship between stress and headaches. For example, one teen described her headaches as a sign that she is stressed: "I get like one headache over my right eye every single time I am stressed out, then I get the headache and I will be like, 'Okay, calm down now" (P1, S1). And almost appropriately, another girl described her stress as being "in her head" which could be interpreted as she had made it up, or that no one could see it. Or this could be more literally interpreted as her stress manifests in her head as head pain: "Yeah, like my stress...I think of as all in my head." (P8, S1)

One teen described having too much to do, leading to a headache and then a "small mental breakdown." 
I've been getting a lot more headaches recently. Just because I've had a lot more stress. I wasn't stressed out at the beginning of the year, but recently, in the past two weeks, I've been a lot more busy and only had like five hours of sleep or four hours of sleep every night. So it's just been a constant. I had a small mental breakdown for one day. It's just been constantly a lot of things to do. (P6, S1)

In general, the teens expressed overwhelm with both their stress and their headaches, however, as they articulated their stories and experiences, their tone and demeanor conveyed a sense of resignation or acceptance, almost as if this was normal, everyday life. Not once did a teen suggest that they or their peers do something to improve their situation.

\section{Sample 2: Archival Sample of 31 Girls with Headache}

Interviews from a sample of 31 teen girls ages 13-18 (Median=16), grades 9-12, represented the archival dataset. See Table 1 for sample characteristics. Demographic data from this sample, including recruitment and consent procedures have been previously published (Björling, 2009).

Pandemonium. In sample 2, several girls reported experiences that were consistent with the Pandemonium theme. One teen described pandemonium in both her mental and physical experience,

It's hard to focus on like, just one thing or another. It's hard to concentrate or something... I often can't sleep well, things like that...One time I got like a stress rash sort of thing, but... and then, you know, headaches sometimes, stomach aches a lot. (P7, S2)

Pandemonium was also articulated in terms of external behavior by one participant,

Interviewer: how do you feel when you're stressed?

P28 (S2): Angry...Like sometimes when I'm stressed I want to inflict harm on everything.

Interviewer: You want to inflict harm on everything?

P28 (S2): Yeah. I think about it, but I don't do it.

Overall, the teen girls described both internal and external pandemonium in their lives. Similar to our findings in study 1 , the archived data also showed evidence of paralysis.

Paralysis. Several girls reported experiences that were consistent with the theme Paralysis. Similar to S1, our archived sample supported evidence of paralysis in relation to the concept of "pressure" - either emotional or physical - that results in reduced function. In the following example, a teen describes the emotional pressure of her schoolwork.

Well, to me stress means that you have a whole bunch of pressure, emotional pressure, like bearing down on your soul, which means if you have so much pressure that you can't function clearly because you're worrying about all the loads that you're trying to carry day to day, daily. (P28, S2)

Another teen described her experience of stress leading to an emotional breakdown which also seemed to fit our theory of paralysis. 
Yeah, sometimes I just like stop caring, you know. Just give up, which isn't a very good thing 'cause then I get less done, but yeah. Sometimes I like have emotional breakdowns where I just have to leave the room, you know. (P25, S2)

Cycling between pandemonium and paralysis. Several girls reported experiences that illustrated the process of cycling between pandemonium and paralysis. One teen described the cycling between pandemonium and paralysis in relation to her headaches.

\begin{abstract}
Pain like throbbing pain in my head [pandemonium], 'cause most -- I'll have the headache in two spots, usually in the front of my head and in the back. Kind of for like sometimes a whole day -- depending on if I stay on my feet all day, but if I rest, it probably will go away...There is a chance it will go away if I lay down [paralysis]. $(P 28, S 2)$
\end{abstract}

Another teen in response to how she responds to stress said, "I guess I would get hyper [pandemonium] or tired [paralysis] from it..." (P6, S2). Overall, we found significant evidence for the pandemonium versus paralysis theory within our archival dataset. Teens from the archival dataset articulated both the internal and external experience of both pandemonium and paralysis as well as the phenomena of cycling between the two.

\title{
Theory Confirmation
}

In accordance with grounded theory procedures, a theory is supported if there is evidence for it elsewhere (Jones \& Alony, 2011). Thus, after developing the theory Pandemonium versus Paralysis, we applied it to archival data from a prior study to identify whether the theory fit data other than the data from which it was generated.

Examination in the media. After exploring the archived data set, we then examined current media examples that may support this new theory. Again, we found this theory applicable to the experiences of teen stress, even those reported in the media. Recently, in a Today Show story about teen stress related to school (Gosk, 2018), a teen was interviewed about her panic attacks, resulting from stress.

Interviewer: What did it [stress] feel like?

Teen: It feels paralyzing. You'll freeze up. You'll sort of feel like there's coils in your body, um, because you're so tightly wound.

A recent report from the New York Times Magazine (Denizet-Lewis, 2017) tells the story of a high school teen boy who was overwhelmed by anxiety. In the article he described his paralysis "All of a sudden I couldn't do anything," he said. "I was so afraid." Similar to our samples, he suffered stomach problems and migraines [pandemonium]. His mother stated that he seemingly, "ran 150 miles per hour [pandemonium] into a brick wall [paralysis]."

Recent research supports this media coverage of teens' mental health issues. In particular, anxiety (Merikangas, 2018) and depressive episodes have been increasing over the past 14 years (Motjabai et al., 2016). These issues parallel our theory, as anxiety symptoms (e.g. racing heart, difficulty concentrating, poor sleep) and depression may also be conceptualized as pandemonium and paralysis, respectively. Moreover, evidence of a strong overlap between anxiety and depressive symptoms (McLaughlin \& King, 2015) also supports our theorized relationship of the cycle between pandemonium and paralysis.

Pandemonium versus paralysis in existing literature. Our grounded theory of pandemonium versus paralysis seemed to resonate with a theory from decades ago by 
Rosenheim and Gaoni (1977) that described the concept of passivity as being characteristic of certain teenagers who were in a "...state of relative 'paralysis'..." (pp. 449, quotes in original) regarding the transition from childhood to adulthood. Thus, passivity may be a normative coping response for teens as they transition toward the increased responsibility and greater autonomy of adulthood.

As previously mentioned, Spencer and colleagues (2016) conducted a qualitative exploration of stress in affluent adolescent girls and their parents. They found a prominent theme, "Drowning in normalized stress" that appears consistent with our theory of pandemonium versus paralysis. In the Spencer et al. study, parents and teachers articulated the extremeness of the teens' stress, whereas the teens accepted this stress as "just the way things are." Moreover, most the teens did not articulate a desire to change the way things are. Some teens even downplayed the significance of the stress while also describing it in somewhat alarming ways. For example, the authors reported that one 11th-grade Caucasian girl described her attitude toward stress as, "It's not that bad. I get a panic attack every so often, but it's not that bad." In addition, many girls spoke about the "meltdowns" and "mental breakdowns" that accompanied their stress (p.10).

We found additional support for our theory in Helvig and Minick's (2013) qualitative study of adolescents with migraine. The authors" theme of "mind overload" seems consistent with our theme of pandemonium. To illustrate, the authors described a teen girl who suggested that she brought the headache upon herself, "because I'm stressing myself out" (p. 21). Furthermore, the authors suggested that teens approach migraine by continuing life as "normal." These findings are consistent with the pattern of stress leading to headache and more importantly, that teens may blame themselves for having headaches or letting stress get out of control. In response, teens may resort to normalizing their experience and their passivity as to further minimize their physiological and psychological pain. The qualitative data from Spencer et al. of "panic attacks" [pandemonium] and "melt-downs" [paralysis] as well as the findings from Helvig and Minick fit well within our pandemonium versus paralysis theory, thus further validating the transferability of this theory.

Anecdotal evidence. This theme also was confirmed during an anecdotal moment for one of the authors (EB). The author's fifteen-year old, male child, also suffers from migraine and school stress. In a recent conversation with his therapist, where he was discussing his school stress, he said that in response to stress, "I want to explode (pandemonium) and I want to lie down (paralysis) at the same time." This moment was another profound, and personal, confirmation of our pandemonium versus paralysis theory.

\section{Discussion}

\section{Fusion \& Experiential Avoidance}

One possible explanation for the theory of Pandemonium versus Paralysis may be that the teen girls were fused with, and experientially avoidant of, their inner experiences. Fusion occurs when the content of one's experience (i.e., thoughts, somatic symptoms, negative emotions) is taken literally as representing real phenomena instead of as merely a 'thought' or a product of the mind's internally re-presenting previously encountered stimuli (Hayes, Strosahl, \& Wilson, 2011). One of the consequences of fusing with inner experience is that the individual assumes the mind's narrative, and associated implications (e.g., the thought 'I'm a failure"), are literally true and therefore must be changed, fixed, or experientially avoided, or else the individual must suffer the consequences (Hayes et al., 2011). Such attempts to avoid one's inner experience often results in behavior geared toward avoiding internal and external stimuli that might paradoxically evoke the painful inner experience. Conversely, to defuse with one's inner experience is to observe the mind's activities and act on it willingly, or not, 
depending on whether it is useful to do so (Hayes et al., 2011). In addition, acceptance of one's inner experience is an ongoing posture of flexibly and openly contacting one's moment-bymoment internal experiences (Hayes et al., 2011).

Given the deleterious effects of fusing with inner experiences (Solé et al., 2015), researchers have increasingly administered mindfulness-based interventions to increase acceptance for, and defusion from, painful inner experiences. Results show consistent benefits for using MBIs to improve health symptoms and quality of life in adults (de Vibe et al., 2017). Whereas, emerging theory and evidence supports mindfulness- and acceptance-based interventions as non-pharmacological approaches to treating headache in adolescents (Chiappedi, Mensi, Termine, \& Balottin, 2016). For instance, in a pilot study of mindfulnessbased intervention for 20 adolescent girls with headache, participants did not report a decrease in headache but they did report increased acceptance of their headache symptoms and an increased sense of agency to cope with their headaches (Hesse, Holmes, Kennedy-Overfelt, Kerr, \& Giles, 2015; Kato, 2018). In another study about using MBIs to reduce chronic pain in adolescents, Ruskin and colleagues' (2017) results showed that that adolescents reported increased pain acceptance and decreased stress. Finally, Björling et al. (2019), found that when teens were actively involved in creating their own mindfulness intervention for headache, the teens' headache activity decreased and engagement in art-based mindfulness activities increased. Taken together, these studies suggest that it may be ideal to target agency in teens, whether it is improving agency over their symptoms using defusion strategies or the agency to design and practice their own interventions, to improve headache symptoms.

Finally, the present data fits with previous research (Björling \& Singh, 2016) that suggests a cyclical relationship between stress and headaches for adolescent girls. Exacerbating this relationship may be an inextricably intertwined cycle of pandemonium that results in moments of paralysis as a natural response to overwhelming experience. Normalizing this experience may be a valid coping strategy for teens as they endure debilitating headaches and extreme stress. However, the act of normalizing may also minimize their own awareness and the awareness of those around them about the difficulty of their lives.

\section{Limitations}

There are several limiting factors that unavoidably impact this study. First, this study included a fairly small sample of adolescent girls attending one high school. Thus, the findings must be interpreted within this context, and transferability of the findings may be limited. Furthermore, future research should investigate possible differences in the experience of headache among teens with diverse demographic characteristics (e.g., gender identity, ethnicity, socioeconomic status). Second, students were asked to miss class to attend our group interviews and thus, we may have captured girls who were less concerned about missing class. Finally, the headache instruments were all retrospective, asking the teens to reflect on their "typical" headache and thus, the resultant recall bias may reduce the validity of these reports. Instead, we considered the instruments to capture each participant's reflection on her typical headache.

\section{Conclusion and Future Research}

This paper presents the grounded theory Pandemonium versus Paralysis, which arose from interviews and surveys of teen girls' experiences of stress and headache. The vacillation between the polarities of pandemonium and paralysis provided a fairly simple theory to fully encompass the wide range of individual and group experiences within our sample. In addition, Pandemonium versus Paralysis helped explain the inextricable, internal relationship between stress and headaches. Furthermore, we found support for the theory by confirming it with archived interviews and examples from recently published media. 
We saw the theory of pandemonium versus paralysis as fitting on both external and internal levels. Regarding the fit with external events, pandemonium was reported as having "too much to do" and feeling overwhelmed by the world and by headache symptoms. Whereas internally, pandemonium was reported as a feeling of being "scattered" or unfocused. Paralysis was also reported externally as extreme headache symptoms which included: severe pain, the feeling of a "tight band" in tension-type headaches, and in the way the disability associated with headaches often stopping the teens from continuing activities. Internal paralysis was indicated as a shutting down or tuning out, sometimes without awareness of it happening.

Pandemonium was most apparent theme noted from the second sample, which was present in virtually all of the girls' descriptions of their symptoms. Less frequently noted was the theme of paralysis. However, when instances of reported paralysis were identified, it appeared obviously related to a cycle with pandemonium. The teens' reports suggested that pandemonium may be a typical, normative experience for adolescents, to which internal paralysis may be a somewhat normal, albeit extreme, coping response. Another theme found in the second sample, was the behavior of procrastination. Many teens described procrastination in relation to their school work and feeling unable to start working, or unable to complete the amount of work which they felt unable to act (paralysis).

There is a great deal to explore related to this initial theory. For instance, do teens without chronic health issues, such as headaches still experience paralysis-type episodes? Do teens with other types of health-related illnesses (e.g. diabetes, asthma or depression) also experience episodes of paralysis? Additionally, it would be interesting to investigate pandemonium versus paralysis quantitatively and explore whether there is a strong correlation between these two polarities. Several researchers have articulated the great need for more research and intervention in the area of adolescent stress (Eiland \& Romeo, 2013; Giota \& Gustafsson, 2016) and headache (Milde-Busch et al., 2011). Consequently, examining real-time stressors and headache triggers may provide essential data to support intervention. Further research is warranted regarding the experience of adolescent girls and interventions to reduce stress and headaches. It is certainly plausible that if pandemonium (via reduced stress and/or headaches) can be minimized, paralysis may no longer be needed as a coping mechanism or response, thus providing an opportunity to develop more adaptive coping mechanisms and ideally increase teens' agency.

\section{Acknowledgments}

We would like to acknowledge all of the adolescent girls who despite their busy schedules, stress, and their headaches, agreed to participate in this research. It is because of these participants that we are beginning to better understand the experience of stress and headaches in adolescence. We would also like to acknowledge our many colleagues who are exploring the experiences of adolescence and join us in the mission to improve mental health for teens.

\section{References}

Albers, L., Straube, A., Landgraf, M. N., Filippopulos, F., Heinen, F., \& von Kries, R. (2015). Migraine and tension type headache in adolescents at grammar school in Germany burden of disease and health care utilization. The Journal of Headache and Pain, 16, 17. http://doi.org/10.1186/s10194-015-0534-4.

Arnsten, A. F. T., \& Shansky, R. M. (2004). Adolescence: Vulnerable period for stress- induced prefrontal cortical function? Introduction to Part IV. Annals of the New York Academy of Sciences, 147(1021), 143-147. https://doi.org/10.1196/annals.1308.017. 
Artinian, B. M., Giske, T., \& Cone, P. H. (2009). Glaserian grounded theory in nursing research: Trusting emergence. New York, NY: Springer.

Björling, E. A. (2009). The momentary relationship between stress and headaches in adolescent girls. Headache: The Journal of Head and Face Pain, 49(8), 1186-1197.

Björling, E. A., \& Singh, N. (2016). Exploring temporal patterns of stress in adolescent girls with headache. Stress and Health, 33(1), 69-79.

Björling, E. A., \& Singh, N. B. (2017). Anger without agency: Exploring the experiences of stress in adolescent girls. The Qualitative Report, 22(10), 2583-2599. Retrieved from: https://search.proquest.com/docview/1949459657?pq-origsite=gscholar.

Björling, E. A., Stevens, C., \& Singh, N. B. (2019) Participatory pilot of an art-based mindfulness intervention for adolescent girls with headache, Art Therapy, 36(2), 86-92. doi: 10.1080/07421656.2019.1609325.

Blaauw, B., Dyb, G., Hagen, K., Holmen, T. L., Linde, M., Wentzel-Larsen, T., \& Zwart, J.-A. (2015). The relationship of anxiety, depression and behavioral problems with recurrent headache in late adolescence - a Young-HUNT follow-up study. The Journal of Headache and Pain, 16, 1-7. http://doi.org/10.1186/1129-2377-16-10.

Carothers, D., \& Parfitt, C. M. (2017). Disability or Language Difference: How Do We Decide?. American Journal of Qualitative Research, 1(1), 1-12.

Charmaz, K., \& Henwood, K. (2017). Grounded theory methods for qualitative psychology: The SAGE handbook of qualitative research in psychology. Thousand Oaks, CA: Sage.

Chiappedi, M., Mensi, M. M., Termine, C., \& Balottin, U. (2016). Psychological therapy in adolescents with chronic daily headache. Current Pain and Headache Reports, 20(1), 1-7. doi 10.1007/s11916-015-0532-x.

Cohen, S. (1988). Perceived stress in a probability sample of the United States. In S. Spacapan \& S. Oskamp (Eds.), The Claremont Symposium on Applied Social Psychology. The Social Psychology of Health (p. 31-67). Sage Publications, Inc.

Cohen, S., Kamarck, T., \& Mermelstein, R. (1994). A global measure of perceived stress. Journal of Health and Social Behavior, 24(4), 385-96. Retrieved from http://www.ncbi.nlm.nih.gov/pubmed/6668417.

Cook, E. C., Chaplin, T. M., \& Stroud, L. R. (2015). The relationship between autonomy and relatedness and adolescents' adrenocortical and cardiovascular stress response. Journal of Youth and Adolescence, 44(11), 1999-2011. http://doi.org/10.1007/s10964-0150331-z.

de Vibe, M., Bjørndal, A., Fattah, S., Dyrdal, G. M., Halland, E., \& Tanner-Smith, E. E. (2017). Mindfulness-based stress reduction (MBSR) for improving health, quality of life and social functioning in adults: A systematic review and meta-analysis. Campbell Systematic Reviews, 13(1), 1-264. doi: 10.4073/csr.2017.11.

Dedoose [Computer software]. (2016). Retrieved from https://www.dedoose.com/.

Denizet-Lewis, B. (2017, October 11). Why are more American teenagers than ever suffering from severe anxiety. The New York Times. Retrieved from https://www.nytimes.com/2017/10/11/magazine/why-are-more-american-teenagersthan-ever-suffering-from-severe-anxiety.html.

Diamond, S., Bigal, M. E., Silberstein, S., Loder, E., Reed, M., \& Lipton, R. B. (2007). Patterns of Diagnosis and Acute and Preventive Treatment for Migraine in the United States: Results from the American Migraine Prevalence and Prevention Study: CME. Headache: The Journal of Head and Face Pain, 47(3), 355-363. http://doi.org/10.1111/j.1526-4610.2006.00631.x.

Draucker, C. B., Martsolf, D. S., Ross, R., \& Rusk, T. B. (2007). Theoretical sampling and category development in grounded theory. Qualitative health research, 17(8), 11371148. https://doi.org/10.1177/1049732307308450. 
Eiland, L., \& Romeo, R. D. (2013). Stress and the developing adolescent brain. Neuroscience, 249(212), 162-71. http://doi.org/10.1016/j.neuroscience.2012.10.048.

Florêncio, C. B. S., Ramos, M. F. H., \& Silva, S. S. da C. (2017). Adolescent perceptions of stress and future expectations. Paidéia (Ribeirão Preto), 27(66), 60-68. http://doi.org/10.1590/1982-43272766201708.

Fuh, J. L., Wang, S. J., Lu, S. R., Liao, Y. C., Chen, S. P., \& Yang, C. Y. (2010). Headache disability among adolescents: A student population-based study: Research submission. Headache, 50(2), 210-218. http://doi.org/10.1111/j.1526-4610.2009.01531.x.

Genizi, J., Srugo, I., \& Kerem, N. C. (2013). The cross- ethnic variations in the prevalence of headache and other somatic complaints among adolescents in Northern Israel. The Journal of Headache and Pain, 14(1), 21. http://doi.org/10.1186/1129-2377-14-21.

Giota, J., \& Gustafsson, J. E. (2016). Perceived demands of schooling, stress and mental health: Changes from grade 6 to grade 9 as a function of gender and cognitive ability. Stress and Health. http://doi.org/10.1002/smi.2693.

Glaser, B. G. (1994). More grounded theory methodology: A reader. Sociology Press.

Glaser, B. G. (2007). All is data. The Grounded Theory Review, 6(2), 1-22. Retrieved from http://groundedtheoryreview.com/2007/03/30/1194/.

Glaser, B. G., \& Holton, J. (2004, May). Remodeling grounded theory. In Forum Qualitative Sozialforschung/Forum: Qualitative Social Research (Vol. 5, No. 2).

Gosk, S. (2018, April 13). Stressed-out teens: Schools take new approaches to avert tragedy [Video file]. TODAY. Retrieved from https://www.today.com/video/stressed-out-teensschools-take-new-approaches-to-avert-tragedy-1210080835688.

Hamilton, J. L., Stange, J. P., Abramson, L. Y., \& Alloy, L. B. (2015). Stress and the development of cognitive vulnerabilities to depression explain sex differences in depressive symptoms during adolescence. Clinical Psychological Science: A Journal of the Association for Psychological Science, 3(5), 702-714. http://doi.org/10.1177/2167702614545479.

Hankin, B. L., Mermelstein, R., \& Roesch, L. (2007). Sex differences in adolescent depression: Stress exposure and reactivity models. Child Development, 78(1), 279-295. http://doi.org/10.1111/j.1467-8624.2007.00997.x.

Helvig, A. W., \& Minick, P. (2013). Adolescents and headaches: maintaining control. Pediatric Nursing, 39(1), 19-25. Retrieved from http://www.ncbi.nlm.nih.gov/pubmed/23540101.

Holton, J. (2018). From Grounded Theory to Grounded Theorizing. In C. Cassel, A. Cunliff, and G. Grady (EDs), The Sage Handbook of Qualitative Business and Management Research Methods, (233-250) London: Sage.

Jones, M., \& Alony, I. (2011). Guiding the use of grounded theory in doctoral studies-An example from the Australian film industry. International Journal of Doctoral Studies, 6, 95-114.

Kato, K. (2018). Cultural Understandings of Mental health: The Role of Language and Ethnic Identity. Journal of Ethnic and Cultural Studies, 5(1), 58-83.

Kendler, K. S., Thornton, L. M., \& Prescott, C. A. (2001). Gender differences in the rates of exposure to stressful life events and sensitivity to their depressogenic effects. American Journal of Psychiatry, 158(4), 587-593. http://doi.org/10.1176/appi.ajp.158.4.587.

Kernick, D., \& Campbell, J. (2009). Measuring the impact of headache in children: A critical review of the literature. Cephalalgia, 29(1), 3-16. http://doi.org/10.1111/j.14682982.2008.01693.x.

Kernick, D., Reinhold, D., \& Campbell, J. L. (2009). Impact of headache on young people in a school population. British Journal of General Practice, 59(566), 678-681. http://doi.org/10.3399/bjgp09X454142. 
King, A. (2008). In vivo coding. In L. M. Given (Ed.), The SAGE encyclopedia of qualitative research methods (pp. 473-473). Thousand Oaks, CA: SAGE Publications.

Kratt, D. (2018). Teachers' perspectives on educator mental health competencies: A qualitative case study. American Journal of Qualitative Research, 2(1), 22-40.

Kudielka, B. M., \& Kirschbaum, C. (2005). Sex differences in HPA axis responses to stress: A review. Biological Psychology, 69(1), 113-32. http://doi.org/10.1016/j.biopsycho.2004.11.009.

Larsson, B., \& Fichtel, A. (2014). Headache prevalence and characteristics among adolescents in the general population: A comparison between retrospect questionnaire and prospective paper diary data. Journal of Headache and Pain, 15(1), 1-10. http://doi.org/10.1186/1129-2377-15-80.

Lima, A. S., Araújo, R. C. de, Gomes, M. R. de A., Almeida, L. R. de, Souza, G. F. F. de, Cunha, S. B., \& Pitangui, A. C. R. (2014). Prevalence of headache and its interference in the activities of daily living in female adolescent students. Revista Paulista de Pediatria, 32(2), 256-261. http://doi.org/10.1590/0103-0582201432212113.

Low, N. C., Dugas, E., O'Loughlin, E., Rodriguez, D., Contreras, G., Chaiton, M., \& O'Loughlin, J. (2012). Common stressful life events and difficulties are associated with mental health symptoms and substance use in young adolescents. BMC Psychiatry, 12(1), 116. http://doi.org/10.1186/1471-244X-12-116.

Mayo Clinic. (2017). Migraine. Retrieved from http://www.mayoclinic.org/diseasesconditions/migraine-headache/symptoms-causes/dxc-20202434.

Mazurka, R., Wynne-Edwards, K. E., \& Harkness, K. L. (2015). Stressful life events prior to depression onset and the cortisol response to stress in youth with first onset versus recurrent depression. Journal of Abnormal Child Psychology, 44(6), 1173-1184. http://doi.org/10.1007/s10802-015-0103-y.

McEwen, B., \& Dhabhar, F. (2002). Stress in adolescent females: Relationship to autoimmune diseases. Journal of Adolescent Health, 30(1), 30-36.

McLaughlin, K. A., \& King, K. (2015). Developmental trajectories of anxiety and depression in early adolescence. Journal of Abnormal Child Psychology, 43(2), 311-323. doi: 10.1007/s10802-014-9898-1.

Merikangas, K. R. (2018). Time trends in the global prevalence of mental disorders in children and adolescents: Gap in data on US youth. Journal of the American Academy of Child and Adolescent Psychiatry, 57(5), 306-307. doi: 10.1016/j.jaac.2018.03.002.

Milde-Busch, A., Blaschek, A., Heinen, F., Borggrafe, I., Koerte, I., Straube, A., Schanking, C., \& von Kries, R. (2011). Associations between stress and migraine and tension-type headache: Results from a school-based study in adolescents from grammar schools in Germany. Cephalalgia, 31(7), 774-785. http://doi.org/10.1177/0333102410390397.

Mojtabai, R., Olfson, M., \& Han, B. (2016). National trends in the prevalence and treatment of depression in adolescents and young adults. Pediatrics, e20161878.

Nardi, B., Francesconi, G., Catena-Dell'Osso, M., \& Bellantuono, C. (2013). Adolescent depression: Clinical features and therapeutic strategies. European Review for Medical and Pharmacological Sciences, 17(11), 1546-1551. Retrieved from https://www.europeanreview.org/wp/wp-content/uploads/1546-15511.pdf.

Østerås, B., Sigmundsson, H., \& Haga, M. (2016). Pain is prevalent among adolescents and equally related to stress across genders. Scandinavian Journal of Pain, 12, 100-107. http://doi.org/10.1016/j.sjpain.2016.05.038.

Peters, M., Huijer Abu-Saad, H., Vydelingum, V., Dowson, A., \& Murphy, M. (2005). The patients' perceptions of migraine and chronic daily headache: A qualitative study. The Journal of Headache and Pain, 6(1), 40-47. http://doi.org/10.1007/s10194-005-0144-7 
Rosenheim, E., \& Gaoni, B. (1977). Defensive passivity in adolescence. Adolescence, 12(48), 449-459.

Ruiz de Velasco, I., Gonzalez, N., Etxeberria, Y., \& Garcia-Monco, J. (2003). Quality of life in migraine patients: A qualitative study. Cephalalgia, 23(9), 892-900. http://doi.org/10.1046/j.1468-2982.2003.00599.x.

Ruskin, D. A., Gagnon, M. M., Kohut, S. A., Stinson, J. N., \& Walker, K. S. (2017). A mindfulness program adapted for adolescents with chronic pain. The Clinical Journal of Pain, 33(11), 1019-1029. https://doi.org/10.1097/AJP.0000000000000490.

Salmela-Aro, K., \& Tynkkynen, L. (2012). Gendered pathways in school burnout among adolescents. Journal of Adolescence, 35(4), 929-939. http://doi.org/10.1016/j.adolescence.2012.01.001.

Schneiderman, N., Ironson, G., \& Siegel, S. D. (2005). Stress and health: Psychological, behavioral, and biological determinants. Annual Review of Clinical Psychology, 1, 607628. http://doi.org/10.1146/annurev.clinpsy.1.102803.144141.STRESS.

Schraml, K., Perski, A., Grossi, G., \& Simonsson-Sarnecki, M. (2011). Stress symptoms among adolescents: The role of subjective psychosocial conditions, lifestyle, and self-esteem. Journal of Adolescence, 34(5), 987-96. http://doi.org/10.1016/j.adolescence.2010.11.010.

Siegel, D. (2015). Brainstorm: The power and purpose of the teenage brain. New York, NY: Jeremy P. Tarcher/Penguin.

Sinclair, D., Purves-Tyson, T. D., Allen, K. M., \& Weickert, C. S. (2014). Impacts of stress and sex hormones on dopamine neurotransmission in the adolescent brain. Psychopharmacology, 231(8), 1581-99. http://doi.org/10.1007/s00213-013-3415-z

Spencer, R., Walsh, J., Liang, B., Mousseau, A. M. D., \& Lund, T. J. (2016). Having it all? A qualitative examination of affluent adolescent girls' perceptions of stress and their quests for success. Journal of Adolescent Research. http://doi.org/10.1177/0743558416670990.

Spicer, J., Werner, E., Zhao, Y., Choi, C. W., Lopez-Pintado, S., Feng, T., Altemus, M., Gyamfi, C., \& Monk, C. (2013). Ambulatory assessments of psychological and peripheral stress-markers predict birth outcomes in teen pregnancy. Journal of Psychosomatic Research, 75(4), 305-313. http://doi.org/10.1016/j.jpsychores.2013.07.001.

Strauss, A., \& Corbin, J. (1994). Grounded theory methodology. Handbook of Qualitative Research, 17, 273-85.

Stroud, L. R., Foster, E., Papandonatos, G. D., Handwerger, K., Granger, D. A., Kivlighan, K. T., \& Niaura, R. (2009). Stress response and the adolescent transition: Performance versus peer rejection stressors. Development and Psychopathology, 21(1), 47-68. http://doi.org/10.1017/S0954579409000042.

Today Show (April 13, 2018). Stressed out teens: Schools take new approaches to avert tragedy. Retrieved from https://www.today.com/video/stressed-out-teens-schools-take-newapproaches-to-avert-tragedy-1210080835688.

Tymula, A., Rosenberg Belmaker, L. A., Roy, A. K., Ruderman, L., Manson, K., Glimcher, P. W., \& Levy, I. (2012). Adolescents' risk-taking behavior is driven by tolerance to ambiguity. Proceedings of the National Academy of Sciences of the United States of America, 109(42), 17135-40. http://doi.org/10.1073/pnas.1207144109.

Wang, S.J., Fuh, J.L., Juang, K.D., \& Lu, S. R. (2009). Migraine and suicidal ideation in adolescents aged 13 to 15 years. Neurology, 72(13), 1146-52. http://doi.org/10.1212/01.wnl.0000345362.91734.b3.

WHO: Headache disorders. (2016). WHO. Retrieved from http://www.who.int/mediacentre/factsheets/fs277/en/. 
Wiklund, M., Malmgren-Olsson, E.-B., Ohman, A., Bergström, E., \& Fjellman-Wiklund, A. (2012). Subjective health complaints in older adolescents are related to perceived stress, anxiety and gender: A cross-sectional school study in Northern Sweden. BMC Public Health, 12, 1-13. http://doi.org/10.1186/1471-2458-12-993.

Wilder, L. K., Sanon, D., Carter, C., \& Lancellot, M. (2017). Narrative Ethnographies of Diverse Faculty in Higher Education:" Moral" Multiculturalism among Competing Worldviews. Journal of Ethnic and Cultural Studies, 4(2), 1-12.

Wilson, S. M., Darling, K. E., Fahrenkamp, A. J., D’Auria, A. L., \& Sato, A. F. (2015). Predictors of emotional eating during adolescents' transition to college: Does body mass index moderate the association between stress and emotional eating? Journal of American College Health, 63(3), 163-170. http://doi.org/10.1080/07448481.2014.1003374.

Wöber-Bingöl, Ç. (2013). Epidemiology of migraine and headache in children and adolescents. Current Pain and Headache Reports, 17(6), 341. http://doi.org/10.1007/s11916-0130341-z.

Wöber-Bingöl, Ç., Wöber, C., Uluduz, D., Uygunoğlu, U., Aslan, T., Kernmayer, M., Zesch, H. E., Gerges, N. T. A., Wagner, G., Siva, A., \&, Steiner, T. J. (2014). The global burden of headache in children and adolescents: Developing a questionnaire and methodology for a global study. The Journal of Headache and Pain, 15(1), 86. http://doi.org/10.1186/1129-2377-15-86.

Yarcheski, A., Mahon, N. E., \& Yarcheski, T. J. (2002). Anger in early adolescent boys and girls with health manifestations. Nursing Research, 51(4), 229-36. Retrieved from http://www.ncbi.nlm.nih.gov/pubmed/12131235.

Manuscript received February 16, 2020

Final revision received April 18, 2020

Accepted April 27, 2020 